\author{
Гусева Светлана Ивановна \\ Независимый исследователь \\ г. Санкт-Петербург, Российская Федерация \\ s_guseva@mail.ru

\section{К вопросу о небуквенных знаках письма Восклицательный знак}

\begin{abstract}
Аннотация
Статья посвящена изучению фраз с восклицательным знаком в пространстве поэтического дискурса на материале стихотворения А. А. Блока. На основе результатов аудиторского эксперимента определяется степень эмоциональной нагруженности фраз в произнесении дикторов - мастеров художественного слова. Обсуждается комплекс причин, вызывающих разную эмоционально-интонационную трактовку дикторами одного и того же поэтического произведения. Отмечается, что многомерность и подвижный семиозис поэтического дискурса, несовпадение пресуппозиций и отсутствие общей коммуникативной базы у автора и читателя приводят к различиям в актуализации дополнительной функции небуквенного знака письма. Экспериментально подтверждается факт высокой степени вариативности интонационных оттенков, графическим референтом которых выступает восклицательный знак. Постулируется наличие иерархии в распределении эмоциональной нагрузки, в частности, её возрастание к концу стихотворения, что, в целом, соответствует стратегии коммуникативной организации высказывания.
\end{abstract}

Ключевые слова: система письма, небуквенные знаки, восклицательный знак, поэтический дискурс, восприятие, эмоциональная нагруженность

(С) Гусева С. И. 2021

Для цитирования: Гусева С. И. К вопросу о небуквенных знаках письма. Восклицательный знак // Теоретическая и прикладная лингвистика. 2021. Вып. 7, № 4. С.29-38. https://doi.org/10.22250/2410-7190_2021_7_4_29_38

\author{
Svetlana I. Guseva \\ Independent researcher \\ Saint Petersburg, Russian Federation \\ s_guseva@mail.ru
}

\title{
Non-letter characters in writing system. Exclamation mark
}

\begin{abstract}
The article examines phrases with the exclamation mark in poetic discourse. Perceptual experiment was used to determine the degree of their emotional load. The material for the study was A. A. Block's poem read by professional performers. The paper discusses a set of reasons that cause different emotional interpretation of the same poetic work and varying intonation patterns employed by the readers. It is argued that the multidimensional and mobile semiosis of poetic discourse, the mismatch of presuppositions and the lack of a common communicative base between the author and the reader account for differences in the actualization of the non-letter symbol additional function in writing. The results of the experiment show high degree of intonation shades variability whose graphic referent is the exclamation mark. The results also indicate the existence of a hierarchy in distributing emotional load, particularly, its increase towards the end of the poem which, in general, corresponds to the strategy of communicative patterns arrangement in the utterance.
\end{abstract}

Keywords: writing system, non-letter symbols, exclamation mark, poetic discourse, perception, emotional load 
For citation: Guseva, S. I. K voprosu o nebukvennykh znakakh pis'ma. Vosklitsatel'nyy znak [To the question of non-letter characters of the letter. Exclamation mark]. Teoreticheskaya i prikladnaya lingvistika [Theoretical and Applied Linguistics], 7(4), 29-38. https://doi.org/10.22250/2410-7190_2021_7_4_29_38

\section{1. Введение [Introduction]}

Письменная речь выполняет одну из главных функций языка - функцию передачи информации из поколения в поколение (просветительскую, цивилизационную функцию), поэтому различные проблемы письма давно находятся в поле зрения исследователей. В меньшей степени это касается так называемых небуквенных знаков письма, остающихся нередко на периферии лингвистического анализа.

Между тем, ещё в 1957 году была опубликована написанная Л. В. Щербой в 1942-1943 гг. монография «Теория русского письма», отдельная глава которой посвящена небуквенным знакам [Щерба, 1983]. Несмотря на сравнительно небольшой объём, с общефонетической точки зрения глава эта, как отметил в предисловии к книге редактор издания Л. Р. Зиндер, представляет исключительный интерес [Зиндер, 1983, с. 4].

К небуквенным обозначениям Л. В. Щерба относит не только знаки пунктуации, но и пробел, прописные буквы как символы членения на слова, а также другие знаки, предназначенные для членения речи и обозначения интонации. Автор по существу предлагает методологию изучения небуквенных знаков, акцентируя внимание на их функциях, взаимосвязи с ритмикой и интонацией, а также с грамматической теорией [Щерба, 1983, с. 123-132].

Десятилетия, прошедшие со времени выхода работы Щербы, характеризуются постепенным ростом интереса лингвистов к различным проблемам пунктуации. Авторы исследований рассматривают с разной степенью глубины проработки такие вопросы, как лингвистический статус знаков пунктуации [Будниченко, 2004], её полифункциональный характер [Шубина, 1999], семиотическое содержание одиночных и двойных знаков препинания [Орехова, 2001], авторская пунктуация и явление пунктуационной синонимии [Мельничук, 2007], роль авторских знаков пунктуации в формировании стратегий и тактик художественного дискурса [Андросова, 2018], особенности функционирования в тексте периферийных знаков пунктуации [Меркулова, 2001] и др. Многие авторы сравнивают пунктуацию с нотным письмом, называя знаки препинания «нотами для чтения» ${ }^{1}$.

Разные подходы к анализу фактов письменной речи приводят к появлению новых понятий и терминов, различиям в структурном описании и определении функциональной нагруженности небуквенных знаков. Нередко это обусловлено тем, какой принцип пунктуации признается ведущим в том или ином языке: синтаксический, семантический или интонационный.

При всём многообразии точек зрения в процессе обсуждения вопросов пунктуации все исследователи сходятся во мнении, что главная функция знаков препинания и прочих небуквенных знаков письма (абзац, прописная буква, пробел) - функция членения речи ${ }^{2}$. Некоторые знаки обладают, кроме того, дополнительными функциями. Так, дополнительной функцией восклицательного знака является обозначение повышенной эмоциональной нагрузки в высказывании. Логично предположить, что использование (или неиспользование) этого знака может служить признаком дискурса определённого

\footnotetext{
${ }^{1}$ Ср.: А. П. Чехов в письме к Н. А. Хлопову, прочитав рассказ драматурга, замечает: «...знаки препинания, служащиие нотами при чтении, расставлены у Вас, как пуговицы на мундире гоголевского городничего. Изобилие многоточий и отсутствие точек» (курсив наш) [Чехов, 1975, с. 199].

2 Т. М. Николаева называет пунктуационные знаки «сегментными указателями», т. к. они выступают в качестве указателей границ сегментов [Николаева, 1968, с. 54].
} 
типа. Совершенно очевидно, что, например, в канцелярском дискурсе (как разновидности официально-делового) употребление восклицательного знака - явление редкое, нетипичное $^{3}$, в то время как для поэтической речи этот знак, несомненно, может рассматриваться в качестве одного из маркеров, отличающих поэтический дискурс от всех иных.

В стихотворной речи эмоция нередко достигает столь высокой интенсивности, что эмоциональная нагрузка может сообщаться каждому отдельному слову и каждому звуковому «обертону» стиха [Макарова, 2005, с. 116]. Яркой иллюстрацией этого утверждения может служить стихотворение А. А. Блока «О, весна, без конца и без краю», в котором на 28 строк приходится 12 восклицательных знаков.

Анализ этого произведения на основе антропоцентрического подхода положен в основу нашего исследования. Антропоцентрический ракурс предполагает при описании языковых фактов учёт человеческого фактора, языковой личности, иными словами, изучение «языкового поведения» как субъекта речи (адресанта), так и реципиента (адресата).

В качестве объекта исследования в работе определены дополнительные функции восклицательного знака, в частности степень экспрессивности фраз, маркированных в поэтическом дискурсе восклицательным знаком.

\section{2. Материал и методика исследования [Material and methods]}

Целью экспериментального исследования было изучение реализации дополнительной функции восклицательного знака в пространстве поэтического дискурса. Задачами исследования предусматривались следующие этапы эксперимента:

- запись из ресурсов Интернета стихотворения А. А. Блока «О, весна, без конца и без краю» в произнесении трёх дикторов - опытных мастеров художественного слова, владеющих навыками нормативно-выразительного чтения 4 ;

- проведение аудиторского эксперимента с целью определения уровня эмоциональной нагруженности поэтического произведения в произнесении каждым из дикторов, в частности фраз с восклицательным знаком, а также всего стихотворения в целом;

- количественный анализ результатов эксперимента и интерпретация полученных данных.

В качестве аудиторов выступили мужчины и женщины (всего 9 человек) с высшим образованием в возрасте от 30 до 75 лет.

Задание аудиторам было сформулировано следующим образом: «Прослушайте художественное чтение стихотворения в исполнении разных дикторов-чтецов (Д1, Д2, Д3) и оцените по 10-балльной шкале уровень эмоциональности прочтения предложений с восклицательным знаком, имея в виду, что самый высокий уровень эмоциональности равен 10 баллам. Заполните предложенную таблицу». На следующем этапе предлагалось оценить уровень эмоциональности прочтения диктором всего стихотворения в целом.

\footnotetext{
${ }^{3}$ В этой связи уместно вспомнить чеховского героя Ефима Фомича Перекладина, который за время служения в качестве коллежского секретаря ни разу не поставил в своих бумагах восклицательного знака: «Что за оказия! Сорок лет писал и ни разу восклицательного знака не поставил... Гм!.. Но когда же он, чёрт длинный, ставится? ... - Марфуша! - обратился он к своей жене, которая часто хвасталась тем, что кончила курс в пансионе. - Ты не знаешь ли, душенька, когда в бумагах ставится восклицательный знак? - Ещё бы не знать! Недаром в пансионе семь лет училась. Наизусть всю грамматику помню. Этот знак ставится при обращениях, восклицаниях и при выражениях восторга, негодования, радости, гнева и прочих чувств. ...Коллежский секретарь задумался. ... Сорок лет писал он бумаги, написал он их тысячи, десятки тысяч, но не помнит ни одной строки, которая выражала бы восторг, негодование или что-нибудь в этом роде. ... - Да нечто в бумагах нужны чувства? Их и бесчувственный писать может...» [Чехов, 1976, с. 269].

${ }^{4}$ Нормативно-выразительное чтение определяется нами, вслед за З.И. Клычниковой, как активный процесс осмысленного чтения, при котором читающий воспроизводит звуковую материю по наиболее частотным и употребительным образцам интонации языка, включающим соответственно фразовое ударение, мелодику, синтагматическую паузацию [Клычникова, 1983, с. 54].
} 
В процессе аудиторского эксперимента по восприятию эмоционально маркированных фраз происходит автоматическое сличение аудитором услышанного с хранящимися у него в памяти моделями коммуникативной организации высказывания [Гусева, 2015 , с. 20]. Знание коммуникативных моделей, стратегий и тактик входит во все типы когнитивных пространств языковой личности; без этого общего «разделенного знания», общего языка общения, общих правил речевого взаимодействия коммуникация невозможна [Койт, Ыйм, 1999, с. 65].

\section{3. Обсуждение результатов [Results and discussion]}

Полученные в ходе аудиторского эксперимента данные были проанализированы, обобщены и представлены в таблицах 1 и 2. Следует пояснить, что в таблицах приведены усредненные значения по всем 9-ти аудиторам.

В связи с основной целью исследования напомним, что восклицательные предложения / фразы выражают эмоциональное отношение к высказываемому. Эмоциональные коннотации определяются (или навязываются) семантикой высказывания и коммуникативной интенцией говорящего. Это могут быть как положительные коннотации (восхищение, радость, вдохновение, вера и т. д.), так и отрицательные (гнев, ирония, презрение, сожаление, тревога и т.д.). В большинстве случаев при помощи интонационных средств восклицательные фразы выражают с повышенной эмоциональной нагрузкой интеллектуальную оценку, обращение или побуждение к действию.

Т а б л и ц а 1. Оценка эмоциональности прочтения фраз с восклицательным знаком в стихотворении А. А. Блока «О, весна без конца и без краю»

[T a $\mathrm{b} 1 \mathrm{e} 1$. Assessment of the emotionality of read phrases with an exclamation mark in A. A. Blok's poem "Oh, spring without end and without edge"]

\begin{tabular}{|c|c|c|c|}
\hline \multirow{3}{*}{ Стихотворение } & \multicolumn{3}{|c|}{ Дикторы-чтецы } \\
\hline & $\begin{array}{c}\text { Д1 } \\
\text { (A. Kутепов) }\end{array}$ & $\begin{array}{c}\text { Д2 } \\
\text { (в. Качалов) }\end{array}$ & $\begin{array}{c}\text { Д3 } \\
\text { (А. Пир-Будагян) }\end{array}$ \\
\hline & \multicolumn{3}{|c|}{$\begin{array}{c}\text { Оценка эмоциональности при прочтении предложений с } \\
\text { восклицательным знаком (по 10-балльной шкале) }\end{array}$} \\
\hline 1 & 2 & 3 & 4 \\
\hline \multicolumn{4}{|l|}{ O, весна без кониа и без краю- } \\
\hline Без кониа и без краю мечта! & 5,3 & 7,5 & 3,8 \\
\hline Узнаю тебя, жизнь! Принимаю! & 4,$2 ; 4,0$ & 7,$0 ; 7,3$ & 3,$8 ; 3,8$ \\
\hline И приветствую звоном щита! & 4,7 & 7,8 & 2,8 \\
\hline \multicolumn{4}{|l|}{ Принимаю тебя, неудача, } \\
\hline И удача, тебе мой привет! & 4,3 & 8,7 & 3,5 \\
\hline \multicolumn{4}{|l|}{ В заколдованной области плача, } \\
\hline В тайне смеха - позорного нет! & 4,7 & 8,2 & 2,8 \\
\hline \multicolumn{4}{|l|}{ Принимаю бессонные споры, } \\
\hline \multicolumn{4}{|l|}{ Утро в завесах темных окна, } \\
\hline \multicolumn{4}{|l|}{ Чтоб мои воспаленные взоры } \\
\hline Раздражала, пьянила весна! & 5,2 & 8,7 & 3,8 \\
\hline
\end{tabular}


Окончание таблицы 1

\begin{tabular}{|c|c|c|c|}
\hline 1 & 2 & 3 & 4 \\
\hline Принимаю пустынные веси! & 4,5 & 7 & 3,5 \\
\hline И колодиьь земныхх городов! & 4,3 & 6,5 & 3,3 \\
\hline \multicolumn{4}{|l|}{ Осветленный простор поднебесий } \\
\hline И томления рабьих трудов! & 4,8 & 6,5 & 3 \\
\hline \multicolumn{4}{|l|}{ И встречаю тебя у порога - } \\
\hline \multicolumn{4}{|l|}{ С буйным ветром в змеиных кудрях, } \\
\hline \multicolumn{4}{|l|}{ С неразгаданным именем бога } \\
\hline \multicolumn{4}{|l|}{ На холодных и сжатых губах... } \\
\hline \multicolumn{4}{|l|}{ Перед этой враждующей встречей } \\
\hline \multicolumn{4}{|l|}{ Никогда я не брошу щита ... } \\
\hline \multicolumn{4}{|l|}{ Никогда не откроешь ты плечи... } \\
\hline Но над нами - хмельная мечта! & 5 & 8 & 3,8 \\
\hline \multicolumn{4}{|l|}{ И смотрю, и вражду измеряю, } \\
\hline \multicolumn{4}{|l|}{ Ненавидя, кляня и любя: } \\
\hline \multicolumn{4}{|l|}{ За мученья, за гибель - я знаю - } \\
\hline Все равно: принимаю тебя! & 5,7 & 8,5 & 3,8 \\
\hline Среднее значение (в баллах) & 4,7 & 7,6 & 3,2 \\
\hline
\end{tabular}

Т а б л и ц а 2. Общая оценка эмоциональности дикторов-чтецов при прочтении стихотворения А. А. Блока «О, весна без конца и без краю»

$[\mathrm{T}$ a $\mathrm{b} 1 \mathrm{e} 2$. General assessment of the emotionality of the readers when reading the poem by A. A. Blok "Oh, spring without end and without edge"]

\begin{tabular}{|c|c|c|c|}
\hline Дикторы-чтецы & $\begin{array}{c}\text { Д 1 } \\
\text { (А. Кутепов) }\end{array}$ & $\begin{array}{c}\text { Д 2 } \\
\text { (В. Качалов })\end{array}$ & $\begin{array}{c}\text { Д3 } \\
\text { (А. Пир-Будагян })\end{array}$ \\
\hline Ср. значение (в баллах) & 6,8 & 9,7 & 5,2 \\
\hline
\end{tabular}

Представленные в таблицах 1 и 2 результаты убедительно свидетельствуют о различиях в эмоциональной окраске прочтения одного и того же стихотворения разными чтецами. Особенно заметны различия между Д2 и Д3 (табл. 1). Данные по этим дикторам разнятся более чем в два раза (7,6 и 3,2 соответственно).

Вместе с тем, несмотря на разную степень эмоциональной трактовки стихотворения в исполнении разными чтецами, нельзя не заметить, что, согласно полученным в ходе аудиторского эксперимента данным, некоторые строки произведения характеризуются одинаково высокими или одинаково низкими значениями относительно остальных значений (табл. 1). Особенно показательны в этом отношении оценки эмоциональности Д1, Д2 и Д3 в рематической части произведения - последней строке: 5,7, 8,5 и 3,8 соответственно («Все равно: принимаю тебя!»). Они закономерно превосходят средние оценки по диктору $(4,7,7,6$ и 3,2$)$, но уступают показателям общей оценки эмоциональности Д1, Д2 и Д3 (6,8, 9,7 и 5,2 соответственно) (табл. 2). Этот факт, по-видимому, объясняется разным характером восприятия стихотворения аудиторами в зависимости от 
поставленной перед ними задачи. В первом прослушивании, определяя степень эмоциональности фраз с восклицательным знаком, аудиторы решали задачу пошагово, а во втором - оценивали эмоциональность стихотворения в целом.

Чтобы понять комплекс причин, вызвавших разную эмоционально-интонационную трактовку мастерами художественного слова одного и того же поэтического произведения, необходим анализ, включающий две стороны любой дискурсивной практики порождение и восприятие дискурса, в нашем случае порождение и восприятие поэтического текста 5 .

Процесс порождения стихотворения, наряду с техникой его сочинения, т. е. приёмами стихосложения, включает пресуппозицию и авторскую интенцию, которые, как правило, определяются событийным контекстом творчества автора. Большинство исследователей полагают, что любое художественное произведение неотделимо от его создателя; замысел автора может быть реконструирован только из текста, в котором он воплощен; физический, реальный автор выражает в своем произведении собственное мировоззрение, а читатель, в свою очередь, реконструирует модель авторского сознания [Андросова, 2018, с. 80-81].

Стихотворение «О, весна, без конца и без краю» было написано А. А. Блоком осенью 1907 г. в период разрыва его взаимоотношений с женой, Л.Д. Менделеевой [Блок, 2019]. Осенью, в кризисный период жизни, в творчестве поэта появляется тема весны и сопутствующей ей мечты... Но образ мечты является сквозным во всей поэзии Блока; для поэта мечта - это надежда на будущее, тайна будущего, предвкушение счастья и движение к нему [Жесткова, 2014, с. 70]. Мечта лирического героя - носителя авторской, сочинительской функции, - роднящего его с реальным автором [Ильенков, 2002 , с.6], воплотилась в звонкие, оптимистические строки, маркированные в тексте восклицательным знаком («O, весна без кониа и без краю - Без конияа и без краю мечта! Узнаю тебя, жизнь! Принимаю! И приветствую звоном щита!» и т. д.).

В конце весны 1907 г. Менделеева уезжает в Шахматово и шлёт оттуда Блоку нежные письма, как будто ничего и не было. Блок отвечает ей тем же [Вульф, 2002, c. 3]. История эта имела продолжение в творчестве поэта осенью того же года в форме восторженного поэтического отклика на события предшествовавшей весны.

Примечательно, что стихотворение «О, весна, без конца и без краю», с восторженной патетикой лирической исповеди, открывает в цикле «Фаина» ${ }^{6}$ группу стихотворений под общим заглавием «Заклятие огнём и мраком». Эта, на первый взгляд, кажущаяся парадоксальность, исчезает, если принять во внимание многомерность поэтического смысла произведения. С одной стороны, стихотворение отражает тяжёлое состояние духа поэта, его мученическую, трагическую судьбу, а с другой - стремление к счастью, движение навстречу новой жизни. А весна, без сомнения, и есть символ новой жизни.

В поэтическом дискурсе как разновидности художественного дискурса отражается сложный духовный мир человека. Многомерность и подвижный семиозис поэтического произведения осложняют его восприятие неподготовленным читателем или слушателем.

\footnotetext{
${ }^{5}$ Поэтический дискурс репрезентируется в поэтическом тексте, который может рассматриваться как дискурсивное звено, непосредственно доступное восприятию и анализу [Евграшкина, 2013, с. 8]. Употребляя термин «поэтический дискурс», мы исходим из ситуационного и социально обусловленного характера дискурсивных практик человека и придерживаемся такого толкования термина, когда под «дискурсом» понимается общая идея о том, что язык структурирован в соответствии с паттернами, которым соответствуют высказывания людей в различных сферах общественной и культурной жизни, например: «медицинский дискурс», «новостной дискурс», «политический дискурс», «религиозный дискурс», «поэтический дискурс» и т. д. [Йоргенсен, Филипс, 2008, с. 352]. Полагаем, что такая дефиниция не противоречит широко известному словарному определению дискурса, данному Н. Д. Арутюновой [ЛЭС, 1990, с. 685], а лишь отражает разные грани лингвистического феномена.

${ }^{6}$ Цикл стихотворений «Фаина» А. А. Блок посвящает актрисе Наталье Волоховой, отношения с которой у поэта начались в ноябре 1907 г. [Вульф, 2002, с. 3].
} 
Феномен восприятия текста рассматривается нами, как и большинством исследователей, в неразрывной связи с его пониманием. Многочисленные работы, посвящённые изучению парадигм понимания, направлены на поиск причин вариативности толкования текстов [Гусева, 2014, с. 11]. Чаще всего вариативность в процессах понимания связывают с различием между индивидуальными полями сигнификатов собеседников [Васильев, 1987, с. 43]. Источником вариативности в процессах понимания называют превращённый характер текста, непрямое отражение действительности, опосредованное миром идеальных образов автора и его знанием этой действительности [Тарасов, Соснова, 1985, с. 32]. Таким образом, уникальность каждого акта восприятия создаётся не только миром идеальных образов автора, но и воспринимающего текст реципиента (читателя, слушателя).

Декодирование сложных поэтических текстов, к числу которых, без сомнения, относится поэзия А.А. Блока, без высокой степени литературной и языковой компетентности представляет известную трудность. В отличие от популярной поэзии мейнстрима, интеллектуальная поэзия, как справедливо отмечается в литературе, является квинтэссенцией творческой работы с языком и его семиотическими возможностями [Евграшкина, 2013, с. 3]. Самоценность слова, изменение его функциональной нагрузки, создание необычных способов построения речи, деформации языковой формы и образа реальности - характерные особенности поэтической дискурсивной деятельности, которые исключают возможность пересказа поэтического произведения другими словами без искажения его сути [Там же, с. 7]. И, как показало наше исследование, порождают разнообразный отклик у воспринимающих поэтический текст реципиентов (читателей, слушателей).

\section{4. Заключение [Conclusion]}

Экспериментальное исследование, проведённое на основе антропоцентрического подхода к анализу фактов языка, убедительно свидетельствует о высокой вариативности устного воспроизведения феноменов, обозначаемых так называемыми небуквенными знаками письма, в частности восклицательным знаком. Изучение эмоциональной насыщенности поэтического произведения в исполнении мастеров художественного слова показало, что однозначная, универсальная звуковая актуализация фраз, маркированных восклицательным знаком, невозможна. В этой связи обозначение знаков пунктуации «нотами для чтения» следует признать весьма и весьма условным.

Многомерность и подвижный семиозис поэтического дискурса, несовпадение пресуппозиций и отсутствие общей коммуникативной базы у автора и читателя приводят к различиям в актуализации дополнительной функции небуквенного знака письма. Таким образом, восклицательный знак выступает на письме графическим референтом интонационных значений высокой степени вариативности.

Изучение устного поэтического текста позволило выявить наличие иерархии в распределении эмоциональной нагрузки, в частности, её возрастание к концу стихотворения, что, в целом, соответствует стратегии коммуникативной организации высказывания.

\section{Библиографический список}

Андросова, 2018 - Андросова Ф.С. Пунктуационные знаки в художественном тексте: коммуникативно-прагматический аспект. СПб. : Изд-во Лань, 2018. 156 с.

Блок, 2019 - Блок Л. Д. И быль и небылицы о Блоке и о себе. Воспоминания. М. ; Берлин : Директ-Медиа, 2019. 86 с.

Будниченко, 2004 - Будниченко Л. А. Экспрессивная пунктуация в публицисти-ческом тексте. На материале языка газет : дис. докт. филол. наук : 10.01.10 / Будниченко Лариса Александровна ; СПбГУ. СПб, 2004. 283 с. 
Васильев, 1987 - Васильев Л. Г. Понимание и научные парадигмы // Языковое общение: единицы и регулятивы. Калинин, 1987. С. 38-43.

Вульф, 2002 - Вульф В. Я. Любовь Дмитриевна Менделеева-Блок: прекрасная Дама русской поэзии. Записала: Серафима Чеботарь // «L"Officiel». 2002. № 37. URL. : http://www.v-vulf.ru/ officiel/officiel-37-4.htm\#

Гусева, 2014 - Гусева С. И. Восприятие спонтанной речи: информационный подход // Филологические науки (Научные доклады высшей школы). 2014. № 3. С. 11-21.

Гусева, 2015 - Гусева С. И. Реализация немецкого вокализма: семантикоцентрический подход // Теоретическая и прикладная лингвистика. 2015. Вып. 1, № 1. С. 16-34.

Евграшкина, 2013 - Евграшкина Е. Е. Языковая природа герметизма в поэтическом дискурсе (на материале немецкоязычной поэзии второй половины XX века) : автореф. дис. канд. филол. наук : 10.02.04 / Евграшкина Екатерина Евгеньевна; Самарский гос. ун-т. Самара, 2013. $22 \mathrm{c}$.

Зиндер, 1983 - Зиндер Л. Р. Предисловие редактора // Щерба Л. В. Теория русского письма. Л. : Наука, 1983. С. 3-6.

Ильенков, 2002 - Ильенков А. И. Лирическая трилогия Александра Блока: формы авторского сознания : автореф. дис. канд. филол. наук : 10.01.01 / Ильенков Андрей Игоревич ; Уральский гос. ун-т. Екатеринбург, 2002. 23 с.

Йоргенсен, Филлипс, 2008 - Йоргенсен М. В., Филлипс Л. Дж. Дискурс-анализ. Теория и метод / пер. с англ. 2-е изд., испр. Изд-во «Гуманитарный центр», 2008. 352 с.

Клычникова, 1983 - Клычникова 3. И. Психологические особенности обучения чтению на иностранном языке : пособие для учителя. М. : Просвещение, 1983. 207 с.

Койт, Ыйм, 1999 - Койт М., Ыйм Х. Диалог с компьютером на естественном языке // Прагматический аспект исследования языка: тр. по русской и славянской филологии. Лингвистика. Новая серия. II. Тарту, 1999. С. 58-67.

ЛЭС, 1990 - Лингвистический энциклопедический словарь. М. : Советская энциклопедия, 1990. 685 c.

Макарова, 2005 - Макарова Л. С. Поэтический дискурс и перевод // Вестник Адыгейского государственного университета. 2005. С. 116-118. URL. : http://vestnik.adygnet.rufilies/2005.2/132/ makarova.

Мельничук, 2007 - Мельничук О. А. Авторская пунктуация и явление пунктуационной синонимии в произведениях современных франкоязычных авторов // Романские языки в прошлом и настоящем : сб. ст. к 80-летию Т. А. Репиной. СПб : Филологический фак. СПбГУ, 2007. С. 178-188.

Меркулова, 2001 - Меркулова И. Г. Периферийные знаки пунктуации в современной французской прозе : дис. канд. филол. наук : 10.02.05 / Меркулова Инна Геннадьевна; Ин-т языкознания Рос. Академии Наук. М., 2001. 167 с.

Николаева, 1968 - Николаева Т. М. О соотношении сегментных указателей и суперсегментных языковых средств // Вопросы языкознания. 1968. № 6. С. 49-57.

Орехова, 2001 - Орехова Н. Н. Пунктуационная система языка: формирование и динамика развития : автореф. дис. докт. филол. наук : 10.02.19 / Орехова Наталья Николаевна ; Воронежский гос. ун-т. Воронеж, 2001. 39 с.

Тарасов, Соснова, 1986 - Тарасов Е. Ф., Соснова М. Л. О формах существования текста // Речевое общение: цели, мотивы, средства. М., 1986. С. 30-44.

Чехов, 1975 - Чехов А. П. Восклицательный знак. Святочный рассказ // Полное собрание сочинений и писем в 30 т. Т. 4 : Рассказы, Юморески, 1885-1886. М. : Наука, 1975. С. 266-270.

Чехов, 1975 - Чехов А. П. Письмо Хлопову Н.А. 13 февраля 1888 г. Москва // Полное собрание сочинений в 30 т. Т. 2 : Письма, 1887 - Сентябрь 1888. М. : Наука, 1975. С. 199-201.

Шубина, 1999 - Шубина Н. Л. Пунктуация в коммуникативно-прагматическом аспекте и ее место в семиотической системе русского языка : дис. д-ра филол. наук : 10.02 .01 / Шубина Наталья Леонидовна ; СПбГУ. СПб, 1999. 455 с.

Щерба, 1983 - Щерба Л. В. Теория русского письма. Л. : Наука, 1983. 134 с. 


\section{References}

Androsova, F. S. (2018). Punktuatsionnye znaki v khudozhestvennom tekste: kommunikativnopragmaticheskiy aspekt [Punctuation marks in fiction: Communicative and pragmatic aspects]. St Petersburg : Lan' Press. (In Russ.).

Blok, L. D. (2019). I byl' i nebylitsy o Bloke i o sebe. Vospominaniya [True story and fables about Block and myself. Memories]. Moscow; Berlin : Direkt-Media. (In Russ.).

Budnichenko, L. A. (2014). Ekspressivnaya punktuatsiya v publitsisticheskom tekste. Na materiale yazyka gazet [Expressive punctuation in non-fiction. Based on newspaper language]: Doctoral in Philological sci. diss. St Pertersburg : St Petersburg State University. (In Russ.).

Vasil'ev, L. G. (1987). Ponimanie i nauchnye paradigmy [Understanding and scientific paradigms]. Yazykovoe obshchenie: edinitsy i regulyativy [Language communication: Units and regulations] (pp. 38-43). Kalinin. (In Russ.).

Vul'f, V. Ya. (2002). Lyubov' Dmitrievna Mendeleeva-Blok: prekrasnaya Dama russkoy poezii. Zapisala: Serafima Chebotar' [Lyubov' Dmitrievna Mendeleeva-Blok: A fair lady of Russian poetry]. L"Officiel, 37. Retrieved from <http://www.v-vulf.ru/officiel/officiel-37-4.htm\#>. (In Russ.).

Guseva, S. I. (2014). Vospriyatie spontannoy rechi: informatsionnyy podkhod [Perception of spontaneous speech: an information approach]. Filologicheskie nauki (Nauchnye doklady vysshey shkoly) [Philological Sciences. Scientific Essays of Higher Education], 3, 11-21. (In Russ.).

Guseva, S. I. (2015). Realizatsiya nemetskogo vokalizma: semantikotsentricheskiy podkhod [Realization of the German vowel system: Semantic-centric approach]. Teoreticheskaya $i$ prikladnaya lingvistika [Theoretical and Applied Linguistics], 1 (1), 16-34. (In Russ.).

Evgrashkina, E. E. (2013). Yazykovaya priroda germetizma v poeticheskom diskurse (na materiale nemetskoyazychnoy poezii vtoroy poloviny $X X$ veka) [Linguistic nature of Hermetism in poetic discourse (Based on second half of the 20th century German poetry)] : Author's abstract of PhD in Philological sci. diss. Samara : Samara State University. (In Russ.).

Zinder, L. R. (1983). Predislovie redaktora [Editor foreword]. Shcherba, L. V. Teoriya russkogo pis'ma [The theory of Russian writing system] (pp. 3-6). Leningrad : Nauka Press. (In Russ.).

Il'enkov, A. I. (2002). Liricheskaya trilogiya Aleksandra Bloka: formy avtorskogo soznaniya [Alexandr Block's lyrical trilogy: Forms of author's thought] : Author's abstract of PhD in Philological sci. diss. Ekaterinburg: Ural State University. (In Russ.).

Jorgensen, M. V., Phillips L. (2008). Diskurs-analiz. Teoriya i metod [Discourse analysis as theory and method]. Translation from English. 2nd edition with corrections. Gumanitarnyy tsentr Press. (In Russ.).

Klychnikova,Z.I. (1983). Psikhologicheskie osobennosti obucheniya chteniyu na inostrannom yazyke [Psychological issues of reading a foreign language]: Teacher's book. Moscow : Prosveshchenie Press. (In Russ.).

Koyt, M., Yym, Kh. (1999). Dialog s komp'yuterom na estestvennom yazyke [Dialog with computer in natural language]. Pragmaticheskiy aspekt issledovaniya yazyka [Pragmatic aspect of language study] : Papers in Russian and Slavic Philology. Lingvistika. Novaya seriya. II [Linguistics. New series. II] (58-67). Tartu. (In Russ.).

Lingvisticheskiy entsiklopedicheskiy slovar' (LES). (1999). Moscow : Sovetskaya entsiklopediya Press.

Makarova, L. S. (2005). Poeticheskiy diskurs i perevod [Poetic discourse and translation]. Vestnik Adygeyskogo gosudarstvennogo universiteta [The Bulletin of the Adyghe State University: Internet Scientific Journal], 116-118. Retrieved from < http://vestnik.adygnet.rufilies/2005.2/132/ makarova>. (In Russ.).

Mel'nichuk, O. A. (2007). Avtorskaya punktuatsiya i yavlenie punktuatsionnoy sinonimii v proizvedeniyakh sovremennykh frankoyazychnykh avtorov [Author punctuation and punctuation synonymy phenomenon in the works of modern French-speaking authors]. Romanskie yazyki $v$ proshlom $i$ nastoyashchem [Romance languages in past and present]: A collection of papers dedicated to 80th anniversary of T. A. Repina birthday (pp. 178-188). St Petersburg: Philological Faculty of St Petersburg State University. (In Russ.). 
Merkulova, I. G. (2001). Periferiynye znaki punktuatsii v sovremennoy frantsuzskoy proze [Periphery punctuation in modern French prose]: PhD in Philological sci. diss. Moscow: Institute of Linguistics, Russian Academy of Sciences. (In Russ.).

Nikolaeva, T. M. (1968). O sootnoshenii segmentnykh ukazateley i supersegmentnykh yazykovykh sredstv [On the interrelation of segmental and suprasegmental linguistic means]. Voprosy yazykoznaniya [Topics in the Study of Language], 6, 49-57. (In Russ.).

Orekhova, N. N. (2001). Punktuatsionnaya sistema yazyka: formirovanie i dinamika razvitiya [Punctuation system of the language: Forming and developing dynamics] : Author's abstract of Doctoral in Philological sci. diss. Voronezh : Voronezh State University. (In Russ.).

Tarasov, E. F., Sosnova, M. L. (1986). O formakh sushchestvovaniya teksta [Forms of text Existance]. Rechevoe obshchenie: tseli, motivy, sredstva [Speech communication: Purposes, motives, means] (pp. 30-44). Moscow. (In Russ.).

Chekhov, A. P. (1975). Vosklitsatel'nyy znak. Svyatochnyy rasskaz [Exclamation mark. A Christmas story]. Polnoe sobranie sochineniy i pisem [Complete collection of essays and letters] in 30 volumes. Vol. 4 : Rasskazy, Yumoreski [Stories and humoresks], 1885-1886 (pp. 266-270). Moscow : Nauka Press. (In Russ.).

Chekhov, A. P. (1975). Pis'mo Khlopovu N. A. 13 fevralya 1888 [A letter to Khlopov N. A. February 13, 1888. Moscow]. Polnoe sobranie sochineniy [Complete collection of essays and letters]. In 30 volumes. Vol. 2 : Pis'ma, 1887 - Sentyabr' 1888 [Letters, 1887 - September, 1888] (pp. 199-201). Moscow : Nauka Press. (In Russ.).

Shubina, N. L. (1999). Punktuatsiya $v$ kommunikativno-pragmaticheskom aspekte $i$ ee mesto $v$ semioticheskoy sisteme russkogo yazyka [Punctuation in communicative and pragmatic aspects and its place in the Russian language semiotic system]: Doctoral of Philological sci. diss. St Petersburg : St Petersburg State University. (In Russ.).

Shcherba, L. V. (1983). Teoriya russkogo pis'ma [The theory of Russian writing system]. Leningrad: Nauka Press. (In Russ.).

Статья поступила в редакцию 29.04.2021; одобрена после рецензирования 30.05.2021; принята к публикации 30.06.2021.

The article was submitted 29.04.2021; approved after reviewing 30.05.2021; accepted for publication 30.06.2021. 